\title{
Less is more: does the addition of barrel staves improve results in endoscopic strip craniectomy for sagittal craniosynostosis?
}

\author{
Benjamin C. Wood, MD, ${ }^{1}$ Edward S. Ahn, MD, ${ }^{2}$ Joanna Y. Wang, BS, ${ }^{2}$ Albert K. Oh, MD, ${ }^{1}$ \\ Robert F. Keating, MD, ${ }^{3}$ Gary F. Rogers, MD, ${ }^{1}$ and Suresh N. Magge, MD $^{3}$
}

Divisions of ${ }^{1}$ Plastic Surgery and ${ }^{3}$ Neurosurgery, Children's National Medical Center, Washington, DC; and ${ }^{2}$ Division of Pediatric Neurosurgery, The Johns Hopkins Hospital, Baltimore, Maryland

\begin{abstract}
OBJECTIVE Endoscopic strip craniectomy (ESC) with postoperative helmet orthosis is a well-established treatment option for sagittal craniosynostosis. There are many technical variations to the surgery ranging from simple strip craniectomy to methods that employ multiple cranial osteotomies. The purpose of this study was to determine whether the addition of lateral barrel-stave osteotomies during ESC improved morphological outcomes.
\end{abstract}

METHODS An IRB-approved retrospective review was conducted on a consecutive series of cases involving ESC for sagittal craniosynostosis at 2 different institutions from March 2008 to August 2014. The patients in Group A underwent ESC and those in Group B had ESC with lateral barrel-stave osteotomies. Demographic and perioperative data were recorded; postoperative morphological outcomes were analyzed using 3D laser scan data acquired from a single orthotic manufacturer who managed patients from both institutions.

RESULTS A total of 73 patients were included (34 in Group A and 39 in Group B). Compared with Group B patients, Group A patients had a shorter mean anesthetic time (161.7 vs 195 minutes; $p<0.01$ ) and operative time (71.6 vs 111 minutes; $p<0.01$ ). The mean hospital stay was similar for the 2 groups (1.2 days for Group A vs 1.4 days for Group B; $p=0.1$. Adequate postoperative data on morphological outcomes were reported by the orthotic manufacturer for 65 patients (29 in Group A and 36 in Group B). The 2 groups had similar improvement in the cephalic index (Cl): Group A, mean change $10.5 \%$ (mean preoperative $\mathrm{Cl} 72.6$, final 80.4) at a mean follow-up of 13.2 months; Group B, mean change $12.2 \%$ (mean preoperative $\mathrm{Cl} 71.0$, final 79.6 ) at a mean follow-up of 19.4 months. The difference was not statistically significant $(p=0.15)$.

CONCLUSIONS Both ESC alone and ESC with barrel staving produced excellent outcomes. However, the addition of barrel staves did not improve the results and, therefore, may not be warranted in the endoscopic treatment of sagittal craniosynostosis.

https://thejns.org/doi/abs/10.3171/2017.1.PEDS16478

KEY WORDS sagittal craniosynostosis; endoscopic strip craniectomy; barrel stave; craniofacial

$\mathrm{T}$ HE use of endoscopically assisted techniques in the treatment of patients with sagittal craniosynostosis has gained increasing acceptance. Following the initial descriptions of this approach by Jimenez and Barone, ${ }^{3,17}$ there have been numerous long-term studies corroborating the safety and relative efficacy of less-invasive methods of managing craniosynostosis, especially sagittal synostosis. ${ }^{18,25,31,33}$ Nevertheless, there is wide variability in the craniofacial literature regarding endoscopic-assist- ed techniques for craniosynostosis, and this has created confusion comparing the reported outcomes of these procedures. ${ }^{5}$ Described techniques include endoscopic strip craniectomy (ESC), endoscopic strip craniectomy plus barrel staves (ESC + BS), and ESC + BS with placement of cinching sutures. ${ }^{13}$

Endoscopic cranial release techniques that use more dissection and a greater number of osteotomies would naturally require greater operative time and have the po-

ABBREVIATIONS $\mathrm{CI}=$ cephalic index; $\mathrm{ESC}$ = endoscopic strip craniectomy; $\mathrm{ESC}+\mathrm{BS}=\mathrm{ESC}$ plus barrel staves.

SUBMITTED August 20, 2016. ACCEPTED January 30, 2017.

INCLUDE WHEN CITING Published online April 14, 2017; DOI: 10.3171/2017.1.PEDS16478. 
tential for more blood loss. Moreover, performing osteotomies across adjacent unaffected cranial sutures risks inducing fusion of those structures with resultant cranial growth impairment, ${ }^{2,15}$ and a longer anesthetic duration in a neonate may have implications related to neural apoptosis. ${ }^{34}$ Advocates of those techniques, however, argue that assuming those risks is vindicated by the improvement in shape and overall clinical outcome. Given the potential for increased morbidity imposed by more extensive endoscopic cranial releases, it is imperative to know whether the added risks are justified.

As with many scientific discoveries, an opportunity to shed some light on this debate arose through happenstance. The 2 major craniofacial centers represented in this investigation are a mere 44 miles apart, and each has an experienced fellowship-trained pediatric neurosurgeon who offers endoscopic strip craniectomy as an early treatment for craniosynostosis. In addition, both pediatric neurosurgeons coincidentally had previously received their fellowship training at the same institution and had learned the endoscopic technique from the same neurosurgeon, Dr. Mark Proctor. One surgeon (E.S.A.) added lateral barrel staves to his technique, while the other surgeon (S.N.M.) did not add barrel staves. Finally, both surgeons sent their postoperative patients to the same orthotic facility (Star Cranial Center in Columbia, Maryland) for postoperative helmet therapy. Thus, each patient, regardless of where his or her procedure was done, underwent nearly identical perioperative management and morphometric laser scan analysis.

This fortuitous situation provided an opportunity to compare the morphological outcomes of patients managed under similar circumstances to determine whether the addition of more extensive cranial osteotomies (i.e., lateral barrel staves) yielded a better cranial morphology than ESC itself.

\section{Methods}

This was a multicenter, IRB-approved, retrospective review of a consecutive series of patients who underwent endoscopically assisted surgery for sagittal craniosynostosis at 2 institutions (Children's National Medical Center and Johns Hopkins Medical Center) between March 2008 and August 2014. Demographic and perioperative data were collected, including age at operation, preoperative cephalic index (CI), type of operation, anesthetic and operative duration, and length of stay. Two surgeons (S.N.M. at Children's National Medical Center, and E.S.A. at Johns Hopkins University) performed all of the operations. Surgical technique at the 2 institutions, aside from the addition of barrel-stave osteotomies, was similar.

\section{Operative Technique: ESC}

The technique for ESC is comparable to that described by Ridgway et al. ${ }^{31}$ The patient is placed in the prone position with the neck extended. Two incisions $(2-3 \mathrm{~cm}$ in length each) are made over the fused sagittal suture: one incision is placed posterior to the anterior fontanelle, and another incision is anterior to the lambdoid sutures. Bur holes are drilled through each incision. Bone is removed anteriorly (through the anterior incision) to the anterior fontanelle and posteriorly (through the posterior incision) to the lambdoid sutures. Dura mater is cleared from the bone between the 2 bur holes, and a $0^{\circ}$ rigid endoscope is used to explore the epidural space between the bur holes and to help clear adhesions. Tessier bone scissors are used to make a 1- to 2-cm strip craniectomy between the 2 bur holes. The entire area is irrigated, hemostasis is achieved, and the incisions are closed with absorbable sutures.

\section{Operative Technique: ESC + BS}

For ESC + BS, the positioning and midline craniectomy are performed in a similar fashion to the procedure described above. The strip craniectomy is slightly wider, at about $3 \mathrm{~cm}$ in width. In addition, bone scissors are used to create cuts in the parietal bone laterally posterior to the coronal and anterior to the lambdoid sutures. A total of four 6- to $8-\mathrm{cm}$ cuts are made-2 anteriorly (behind coronal sutures) and 2 posteriorly (anterior to lambdoid sutures). The cuts are made down to the area of the squamosal sutures. The parietal bones are then manipulated slightly to widen the midline craniectomy opening. Closure of the scalp is similar to that described above.

\section{Helmet Therapy and Outcome Analysis}

All patients underwent postoperative helmet therapy instituted by the same orthotic company (Star Cranial) and using the same treatment protocols. Postoperative outcomes were analyzed using the quantitative imaging data acquired from laser scans from the helmet manufacturer (Fig. 1). The final CI and follow-up duration were defined by the last scan obtained by the orthotic manufacturer; in some instances, the last scan was obtained after discontinuation of the helmet therapy.

\section{Results}

A total of 73 patients underwent endoscopically assisted treatment of sagittal craniosynostosis (Table 1). All patients underwent postoperative helmet therapy, performed by the same orthotic manufacturer. There were 34 patients in whom ESC alone was performed (Group A), and 39 patients who underwent ESC + BS (Group B). The patients' average age at operation was 3.2 months in Group A and 2.7 months in Group B. Group A had a mean anesthetic duration of 161.7 minutes and mean operative time of 71.6 minutes, compared with 195 minutes $(\mathrm{p}<0.01)$ and 111

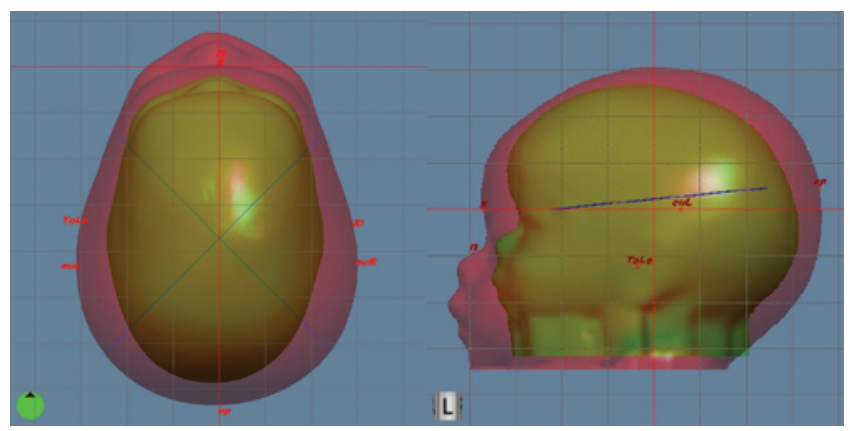

FIG. 1. Quantitative cranial imaging obtained by the orthotic manufacturer. Figure is available in color online only. 
TABLE 1. Demographic and operative data

\begin{tabular}{lccc}
\hline \multicolumn{1}{c}{ Variable } & $\begin{array}{c}\text { Group A } \\
(\text { ESC) }\end{array}$ & $\begin{array}{c}\text { Group B } \\
(\text { ESC + BS) }\end{array}$ & $\begin{array}{c}p \\
\text { Value }\end{array}$ \\
\hline No. of patients & 34 & 39 & \\
\hline Age at surgery (mos) & 3.2 & 2.7 & \\
\hline Follow-up (mos) & 13.2 & 19.4 & \\
\hline Hospital LOS (days) & 1.2 & 1.4 & 0.1 \\
\hline Op time (mins) & 71.6 & 111 & $<0.01$ \\
\hline Anesthetic time (mins) & 161.7 & 195.0 & $<0.01$ \\
\hline ESC = endoscopic strip craniectomy; ESC + BS = ESC plus barrel staves; LOS \\
$=$ length of stay.
\end{tabular}

minutes ( $\mathrm{p}<0.01$ ) for Group B (Fig. 2). The average estimated blood loss was $38 \mathrm{ml}$ in Group A, and $44.5 \mathrm{ml}$ in Group B. The average postoperative length of stay was 1.2 days for Group A and 1.4 days for Group B $(\mathrm{p}=0.1)$.

Adequate postoperative data were recorded by the orthotic manufacturer in a total of 65 cases (29 in Group A and 36 in Group B; Table 2). In Group A, the mean preoperative CI was 72.6 and the mean immediate postoperative $\mathrm{CI}$ was 73.8 , compared with 71.0 and 73.6 for Group B. The mean final CI was 80.4 for Group A and 79.6 for Group B $(\mathrm{p}=0.34)$. The mean percentage change in CI was $10.5 \%$ (SD 5\%) for Group A, and $12.2 \%$ (SD 5\%) for Group B $(p=0.15)$. The mean follow-up period was 13.2 months for Group A and 19.4 months for Group B.

\section{Discussion}

Since the initial descriptions of an endoscopic technique for the treatment of sagittal craniosynostosis by Jimenez and Barone, ${ }^{3,17}$ multiple groups have published series reporting their outcomes for minimally invasive approaches in the treatment of sagittal synostosis. ${ }^{4-7,13,14,18-21 \text {, }}$ $25,28,31,33,35,37$ The addition of a helmet orthosis after surgery has served as a key adjunct, enabling less-invasive surgical methods to achieve cranial shape comparable to that of traditional open cranial vault remodeling, with significant reductions in anesthesia and hospitalization times and overall cost of care. . $^{1,8,9,22,27,36}$

The definition of "endoscopic" surgery for craniosynostosis is widely variable, making comparison of techniques challenging. ${ }^{5}$ The simplest and least invasive method of endoscopic strip craniectomy (ESC) is simple suturectomy. This technique has been described in multiple studies ${ }^{4,31}$ and involves the least amount of dissection and bone cuts. It is a remarkably straightforward method, but there is variability in the width of the craniectomy segment removed by different surgeons. Other surgeons employ the use of barrel-staving osteotomies in addition to an endoscopic suturectomy. This requires a more extensive dissection to permit the lateral osteotomies. In addition to these cranial release procedures, several surgeons have stabilized the bony contour by adding cinching sutures to decrease the anterior-posterior dimension, analogous to an open pi procedure. ${ }^{13}$ Each additional step adds potential morbidity and blood loss to the suturectomy procedure, but quantitative comparisons among these technical modifications are lacking.

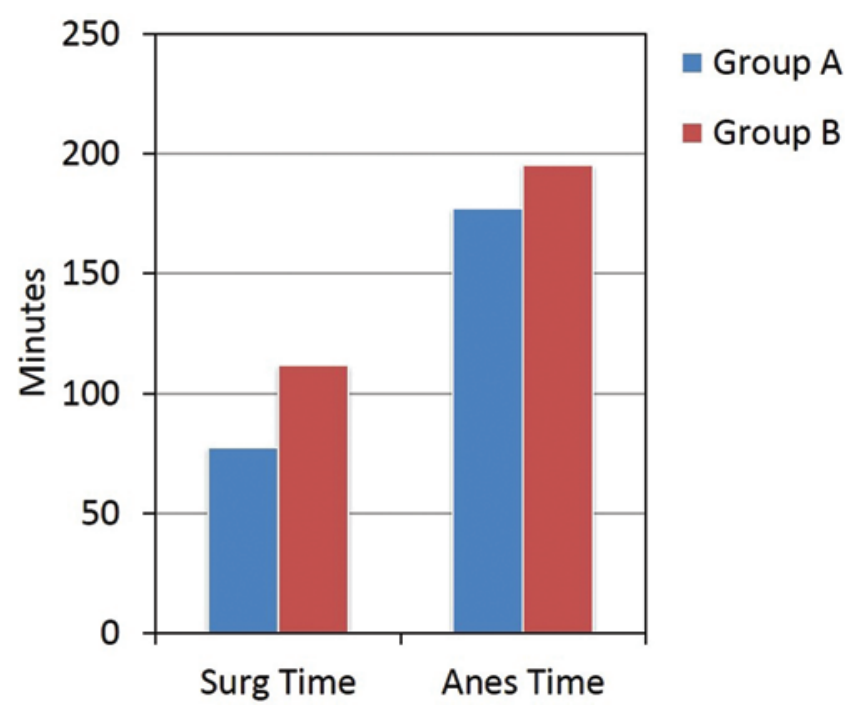

FIG. 2. Comparison of operative (Surg) and anesthetic (Anes) duration in Group A (ESC) and Group B (ESC + BS). Figure is available in color online only.

This investigation is one of the first studies to compare the outcomes of 2 types of minimally invasive techniques for managing sagittal craniosynostosis. Our results demonstrate that the addition of lateral barrel staves to ESC provided no significant benefit in CI, but significantly increased operative time and anesthetic duration. The estimated blood loss was slightly greater in Group B than Group A, but the difference was not statistically significant. While the differences among groups were minor, these procedures are done in very young patients (about 3 months of age), and additional exposure to anesthetic agents at this time may increase the risk of neural apoptosis. ${ }^{11,16,26,29,30,34}$ Moreover, we remain concerned about the impact of more-extensive surgical dissection and cranial osteotomies on the growth potential of adjacent patent sutures. $^{2}$ Although reported in 1 patient treated endoscopically, ${ }_{15}^{15}$ there is a stronger body of literature attributing premature closure of previously patent sutures to association with more-invasive procedures such as open cranial vault remodeling. 12,23,24,32 Implications for early closure of uninvolved sutures may include reoperation for elevated intracranial pressure, obviating the presumed benefits of a less invasive initial approach. In the absence of evidence that the longer and more invasive ESC + BS procedure leads to discernible benefits to cranial shape, we advocate performing ESC without barrel-stave osteotomies.

TABLE 2. Postoperative outcomes

\begin{tabular}{lccc}
\hline \multicolumn{1}{c}{ Variable } & $\begin{array}{c}\text { Group A } \\
(\mathrm{ESC})\end{array}$ & $\begin{array}{c}\text { Group B } \\
(\mathrm{ESC}+\mathrm{BS})\end{array}$ & $\begin{array}{c}\mathrm{p} \\
\text { Value }\end{array}$ \\
\hline No. of patients & 29 & 36 & \\
\hline Preop Cl & 72.6 & 71 & \\
\hline Immediate postop Cl & 73.8 & 73.6 & \\
\hline Final Cl & 80.4 & 79.6 & 0.34 \\
\hline Mean change in $\mathrm{Cl}(\mathrm{SD})$ & $10.5 \%(5 \%)$ & $12.2(5 \%)$ & 0.15 \\
\hline
\end{tabular}

$\mathrm{Cl}=$ cephalic index: $($ width/length $) \times 100$. 
Dlouhy et al. ${ }^{10}$ recently published an excellent study in which they compared wide suturectomy with barrel staves versus narrow suturectomy without barrel staves. Their study involved 28 patients (14 patients in each group) and demonstrated that wide suturectomy with barrel staves did not improve outcome at 1 year of age. Our study had a larger patient group (73 patients total), and somewhat longer follow-up time. In addition, the craniectomy widths were more similar in the 2 groups of our study, which leads to a more direct comparison of the effect of barrel staves. Our study was slightly different but the results agree with and expand upon their data.

There are limitations with this study. First, the study was performed at 2 distinct craniofacial centers, and each group (procedure type) was managed by a different surgeon. It is possible, although unlikely, that institutional differences in perioperative recording may have accounted for some of the observed variation in anesthetic and operative times. Second, we used CI to report overall improvement and change in cranial shape. The validity of this measurement, which has been the main method for reporting phenotype and cranial morphology of sagittal craniosynostosis, has been questioned, as it may not adequately reflect 3D form. Third, the mean duration of follow-up was a few months longer for Group B than for Group A, and it is unclear whether that could have affected the results. This difference in duration of followup was because some patients in Group B had follow-up scans long after discontinuation of helmeting. Although the comparison could have been made more uniform by limiting the analysis to a 9- to 12-month window after the procedure, we opted to include the additional data points for a more complete picture. Fourth, while the addition of barrel staves was the major difference in technique between the 2 groups, craniectomy width was slightly wider $(3 \mathrm{~cm})$ in the ESC + BS group than in the ESC group (1-2 $\mathrm{cm})$. If anything, we would expect this to help the results of the ESC + BS group, but we do not see any significant difference. Lastly, the barrel-staving procedure used in this report may vary from the techniques used by other authors, and thus the findings may not be translatable to all other types of ESC + BS. We would encourage further studies comparing the results of more extensive endoscopic procedures to simple ESC.

\section{Conclusions}

The addition of lateral barrel staves during ESC increased operative and anesthesia times but provided no significant benefit over ESC without barrel staves. Consequently, the addition of lateral barrel staves to ESC may not be indicated for the treatment of isolated sagittal craniosynostosis.

\section{Acknowledgments}

We would like to thank Star Cranial Center (Columbia, MD) for assistance with providing laser scans for analysis.

\section{References}

1. Abbott MM, Rogers GF, Proctor MR, Busa K, Meara JG:
Cost of treating sagittal synostosis in the first year of life. J Craniofac Surg 23:88-93, 2012

2. Adamo MA, Pollack IF: A single-center experience with symptomatic postoperative calvarial growth restriction after extended strip craniectomy for sagittal craniosynostosis. J Neurosurg Pediatr 5:131-135, 2010

3. Barone CM, Jimenez DF: Endoscopic craniectomy for early correction of craniosynostosis. Plast Reconstr Surg 104:1965-1975, 1999

4. Berry-Candelario J, Ridgway EB, Grondin RT, Rogers GF, Proctor MR: Endoscope-assisted strip craniectomy and postoperative helmet therapy for treatment of craniosynostosis. Neurosurg Focus 31(2):E5, 2011

5. Bonfield CM, Lee PS, Adamo MA, Pollack IF: Surgical treatment of sagittal synostosis by extended strip craniectomy: cranial index, nasofrontal angle, reoperation rate, and a review of the literature. J Craniomaxillofac Surg 42:1095-1101, 2014

6. Brown L, Proctor MR: Endoscopically assisted correction of sagittal craniosynostosis. AORN J 93:566-581, 2011

7. Cartwright CC, Jimenez DF, Barone CM, Baker L: Endoscopic strip craniectomy: a minimally invasive treatment for early correction of craniosynostosis. J Neurosci Nurs 35:130-138, 2003

8. Chan JW, Stewart CL, Stalder MW, St Hilaire H, McBride L, Moses MH: Endoscope-assisted versus open repair of craniosynostosis: a comparison of perioperative cost and risk. J Craniofac Surg 24:170-174, 2013

9. Di Rocco C, Tamburrini G, Pietrini D: Blood sparing in craniosynostosis surgery. Semin Pediatr Neurol 11:278-287, 2004

10. Dlouhy BJ, Nguyen DC, Patel KB, Hoben GM, Skolnick GB, Naidoo SD, et al: Endoscope-assisted management of sagittal synostosis: wide vertex suturectomy and barrel stave osteotomies versus narrow vertex suturectomy. J Neurosurg Pediatr 25:674-678, 2016

11. Gleich S, Nemergut M, Flick R: Anesthetic-related neurotoxicity in young children: an update. Curr Opin Anaesthesiol 26:340-347, 2013

12. Greene CS Jr: Pancraniosynostosis after surgery for single sutural craniosynostosis. Pediatr Neurosurg 29:127-132, 1998

13. Hashim PW, Patel A, Yang JF, Travieso R, Terner J, Losee JE, et al: The effects of whole-vault cranioplasty versus strip craniectomy on long-term neuropsychological outcomes in sagittal craniosynostosis. Plast Reconstr Surg 134:491-501, 2014

14. Hinojosa J, Esparza J, Muñoz MJ: Endoscopic-assisted osteotomies for the treatment of craniosynostosis. Childs Nerv Syst 23:1421-1430, 2007

15. Jenkins GH, Smith NR, McNeely PD: Pancraniosynostosis following endoscope-assisted strip craniectomy and helmet orthosis for sagittal suture craniosynostosis in a nonsyndromic patient. J Neurosurg Pediatr 12:77-79, 2013

16. Jevtovic-Todorovic V: Functional implications of an early exposure to general anesthesia: are we changing the behavior of our children? Mol Neurobiol 48:288-293, 2013

17. Jimenez DF, Barone CM: Endoscopic craniectomy for early surgical correction of sagittal craniosynostosis. J Neurosurg 88:77-81, 1998

18. Jimenez DF, Barone CM: Endoscopic technique for sagittal synostosis. Childs Nerv Syst 28:1333-1339, 2012

19. Jimenez DF, Barone CM: Endoscopy-assisted wide-vertex craniectomy, "barrel-stave" osteotomies, and postoperative helmet molding therapy in the early management of sagittal suture craniosynostosis. Neurosurg Focus 9(3):e2, 2000

20. Jimenez DF, Barone CM, Cartwright CC, Baker L: Early management of craniosynostosis using endoscopic-assisted strip craniectomies and cranial orthotic molding therapy. Pediatrics 110:97-104, 2002 
21. Jimenez DF, Barone CM, McGee ME, Cartwright CC, Baker CL: Endoscopy-assisted wide-vertex craniectomy, barrel stave osteotomies, and postoperative helmet molding therapy in the management of sagittal suture craniosynostosis. J Neurosurg 100 (5 Suppl Pediatrics):407-417, 2004

22. Johnson JO, Jimenez DF, Barone CM: Blood loss after endoscopic strip craniectomy for craniosynostosis. J Neurosurg Anesthesiol 12:60, 2000

23. Kuang A, Selden NR: Secondary cranial vault remodeling for restenosis after primary sagittal synostosis repair. Pediatr Neurosurg 50:104-108, 2015

24. Kuang AA, Jenq T, Didier R, Moneta L, Bardo D, Selden NR: Benign radiographic coronal synostosis after sagittal synostosis repair. J Craniofac Surg 24:937-940, 2013

25. Le MB, Patel K, Skolnick G, Naidoo S, Smyth M, Kane A, et al: Assessing long-term outcomes of open and endoscopic sagittal synostosis reconstruction using three-dimensional photography. J Craniofac Surg 25:573-576, 2014

26. Loftis GK, Collins S, McDowell M: Anesthesia-induced neuronal apoptosis during synaptogenesis: a review of the literature. AANA J 80:291-298, 2012

27. Meier PM, Goobie SM, DiNardo JA, Proctor MR, Zurakowski D, Soriano SG: Endoscopic strip craniectomy in early infancy: the initial five years of anesthesia experience. Anesth Analg 112:407-414, 2011

28. Murad GJ, Clayman M, Seagle MB, White S, Perkins LA, Pincus DW: Endoscopic-assisted repair of craniosynostosis. Neurosurg Focus 19(6):E6, 2005

29. Perna RB, Loughan AR, Le JA, Hertza J: Prenatal and perinatal anesthesia and the long-term cognitive sequelae: a review. Appl Neuropsychol Child 4:65-71, 2015

30. Rappaport B, Mellon RD, Simone A, Woodcock J: Defining safe use of anesthesia in children. N Engl J Med 364:13871390, 2011

31. Ridgway EB, Berry-Candelario J, Grondin RT, Rogers GF, Proctor MR: The management of sagittal synostosis using endoscopic suturectomy and postoperative helmet therapy. J Neurosurg Pediatr 7:620-626, 2011

32. Seruya M, Tan SY, Wray AC, Penington AJ, Greensmith AL, Holmes AD, et al: Total cranial vault remodeling for isolated sagittal synostosis: part I. Postoperative cranial suture patency. Plast Reconstr Surg 132:602e-610e, 2013

33. Shah MN, Kane AA, Petersen JD, Woo AS, Naidoo SD, Smyth MD: Endoscopically assisted versus open repair of sagittal craniosynostosis: the St. Louis Children's Hospital experience. J Neurosurg Pediatr 8:165-170, 2011

34. Sinner B, Becke K, Engelhard K: General anaesthetics and the developing brain: an overview. Anaesthesia 69:10091022,2014
35. Stelnicki EJ: Endoscopic treatment of craniosynostosis. Atlas Oral Maxillofac Surg Clin North Am 10:57-72, 2002

36. Vogel TW, Woo AS, Kane AA, Patel KB, Naidoo SD, Smyth MD: A comparison of costs associated with endoscopeassisted craniectomy versus open cranial vault repair for infants with sagittal synostosis. J Neurosurg Pediatr 13:324-331, 2014

37. Wong RK, Emelin JK, Meltzer HS, Levy ML, Cohen SR: Nonsyndromic craniosynostosis: the Rady Children's Hospital approach. J Craniofac Surg 23 (7 Suppl 1):2061-2065, 2012

\section{Disclosures}

The authors report no conflict of interest concerning the materials or methods used in this study or the findings specified in this paper.

\section{Author Contributions}

Conception and design: Wood, Ahn, Oh, Keating, Rogers, Magge. Acquisition of data: Wood, Ahn, Wang, Magge. Analysis and interpretation of data: Wood, Ahn, Oh, Rogers, Magge. Drafting the article: Wood, Ahn, Oh, Rogers, Magge. Critically revising the article: Wood, Ahn, Oh, Keating, Rogers, Magge. Reviewed submitted version of manuscript: all authors. Approved the final version of the manuscript on behalf of all authors: Wood. Statistical analysis: Wood, Oh, Magge. Administrative/technical/ material support: Wood. Study supervision: Ahn, Keating, Rogers, Magge.

\section{Supplemental Information \\ Previous Presentations}

Portions of this work were presented as proceedings at the American Society of Plastic Surgeons: The Meeting 2015, Boston, MA, October 16-20, 2015; Northeastern Society of Plastic Surgeons 32nd Annual Meeting, Philadelphia, PA, September 18-20, 2015; International Society of Craniofacial Surgery 16th Biennial Congress, Tokyo, Japan, September 14-18, 2015; and International Society of Pediatric Neurosurgery, Kobe, Japan, October 23-27, 2016.

\section{Correspondence}

Benjamin C. Wood, Division of Plastic Surgery, Children's National Medical Center, 111 Michigan Ave. NW, Washington, DC 20010. email: wood.benjaminc@gmail.com. 